\title{
Anticoagulants and mitral valvotomy: a nine-year survey
}

\author{
S. F. STEPHEN S O N
}

From the Thoracic Surgical Centre, Hill Top Hospital, Bromsgrove, Worcs

Systemic embolism, occurring during either the operation or in the post-operative period, remains a serious complication of mitral valvotomy. It causes many deaths and those who survive it may suffer a crippling permanent disability. Since 1955 anticoagulants have been widely used at the Hill Top Hospital, Bromsgrove, for the purpose of preventing clot formation and subsequent dissemination at operation, and the results of this therapy form the basis of this study.

\section{INCIDENCE AND CAUSATION}

Systemic emboli associated with mitral valvotomy occur in about $5 \%$ of patients and carry a mortality of about $2 \%$, which is nearly half the total mortality of this operation. At least two-thirds of all emboli affect the cerebral circulation. Table I shows the incidence of embolism in various published series; the figures collected for the

T A B L E I

INCIDENCE OF EMBOLISM COMPLICATING MITRAL VALVOTOMY

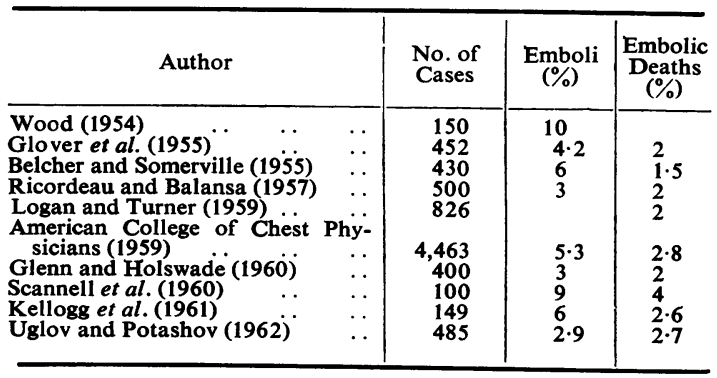

American College of Chest Physicians, being the work of many surgeons, are probably fairly representative of the results in most centres.

Systemic embolism is much commoner in the presence of atrial fibrillation. When clot forms in the left atrium it may quickly become adherent and then organized, or it may be embolized. Wood (1954) pointed out that old clot might be dislodged at operation, but not spontaneously, but that fresh clot was dangerous at all times. Belcher and Somerville (1955), in a detailed survey, showed that if old clot was found at operation the chance of an embolus occurring was $10 \%$, whereas if fresh clot was found this possibility rose to $25 \%$.

The dangers of clot are very much in the surgeon's mind when he approaches the left atrial appendage, and various methods of reducing clot dissemination are available to him. Clamps must be used with caution, and the atrium and its appendage should be flushed out by allowing blood to escape before inserting the finger. External pressure on the carotid arteries in the neck gives some protection. Isolation and compression of the innominate and left carotid arteries within the chest is usually effective, but it is sometimes difficult and may be dangerous if the pulmonary arteries are grossly enlarged. It may also damage the vessels themselves or cause cerebral anoxia (Glover, Iaia, O'Neill, and Janton, 1955). None of these methods gives complete protection.

A different way of tackling the problem is to reduce the formation of fresh atrial clot by administering anticoagulants. Anticoagulant therapy is widely used in the medical treatment of mitral valve disease with embolic complications. Foley and Wright (1956) reported a series of patients with repeated emboli in which the incidence fell to one-eleventh under anticoagulant therapy, and Szekely (1964) found that the emboli were most common during the first year after the onset of atrial fibrillation, and that anticoagulants gave marked protection during this time. Provided that the risks of valvotomy are not greatly increased by altering the clotting power of the blood, there are therefore good reasons for using the protection given by anticoagulants to cover the operation itself and especially the preoperative period. 


\section{MATERIAL}

Between January 1955 and December 1963 mitral valvotomy was performed by four surgeons on 267 patients, of whom 74 were male and 193 female. The age limits were 16 and 62 and the age distribution is shown in Table II.

T A B L E II

AGE DISTRIBUTION OF 267 CASES OF MITRAL VALVOTOMY

\begin{tabular}{l|c|c|c|c|c|c|c|c}
\hline & \multicolumn{9}{|c}{ Age (yr.) } \\
\cline { 2 - 6 } & $0-20$ & $21-30$ & $31-40$ & $41-50$ & $51-60$ & $61-70$ & Total \\
\hline Regular rhythm & 5 & 42 & 54 & 39 & 5 & 1 & 146 \\
Atrial fibrillation & 0 & 8 & 35 & 58 & 20 & 0 & 121 \\
\hline & 5 & 50 & 89 & 97 & 25 & 1 & 267 \\
\hline
\end{tabular}

Atrial fibrillation was present in 121 patients $(45 \%)$. Twelve of the valvotomies were second operations for restenosis; this, however, does not represent the true incidence of restenosis, since some patients have undergone re-operation at other hospitals. Transventricular valvotomy using a Tubbs dilator has been the method employed in most patients since 1958, but there is no evidence that this technique has had any influence on the incidence of embolism.

A pre-operative assessment of disability, using the classification of Baker, Brock, Campbell, and Wood (1952), is given in Table III.

TA B LE III

DISABILITY OF 267 PATIENTS WHO UNDERWENT MITRAL \begin{tabular}{c|c} 
VALVOTOMY \\
\hline \begin{tabular}{c|c} 
Grade of \\
Disability
\end{tabular} & $\begin{array}{c}\text { No. of } \\
\text { Patients }\end{array}$ \\
\hline 0 & 0 \\
1 & 3 \\
2 & 119 \\
3 & 125 \\
4 & 20 \\
\hline Total & 267 \\
\hline
\end{tabular}

ANTICOAGULANT THERAPY Since 1955 anticoagulants have been given to nearly all patients with atrial fibrillation, and to those in regular rhythm with a history of systemic or pulmonary embolism, thrombophlebitis or marked pulmonary hypertension. Thus anticoagulant therapy was given to 114 of 121 patients with atrial fibrillation and to 35 of 146 patients in regular rhythm. Phenindione (Dindevan) was used in all treated cases. It was usually given for at least two weeks before operation to maintain a level of prothrombin activity between 20 and $30 \%$, which is allowed to rise to between 30 and $50 \%$ by the day of operation. Treatment is continued after operation, at least until the patient leaves hospital, and is discontinued gradually.

Variations in duration and in prothrombin levels have occurred. Surgeons have variable and sometimes changing opinions about the optimum level at the time of operation, and in some patients the maintenance of a steady prothrombin level is difficult or impossible.

PRE-OPERATIVE EMBOLISM AND ATRIAL CLOT Table IV summarizes the incidence of embolism and atrial clot and the results of operation.

T A B L E I V

INCIDENCE OF SYSTEMIC EMBOLISM AND ATRIAL CLOT

\begin{tabular}{|c|c|c|c|c|c|}
\hline & & \multirow{2}{*}{$\begin{array}{l}\text { Regular } \\
\text { Rhythm }\end{array}$} & \multirow{2}{*}{$\begin{array}{c}\text { Atrial } \\
\text { Fibrilla- } \\
\text { tion }\end{array}$} & \multicolumn{2}{|c|}{ Total } \\
\hline & & & & No. & $\%$ \\
\hline $\begin{array}{l}\text { No. of patients .. } \\
\text { Pre-operative emboli } \\
\text { Atrial clot } \\
\text { Operative emboli } \\
\text { Embolic deaths .. } \\
\text { Total deaths .. }\end{array}$ & $\begin{array}{l}\cdots \\
\cdots \\
\cdots \\
\cdots \\
\cdots\end{array}$ & $\begin{array}{r}146 \\
8 \\
9 \\
5^{1} \\
0 \\
7\end{array}$ & $\begin{array}{r}121 \\
27 \\
35 \\
8^{2} \\
3 \\
10\end{array}$ & $\begin{array}{r}267 \\
35 \\
44 \\
13 \\
3 \\
17\end{array}$ & $\begin{array}{r}13.1 \\
16.5 \\
4.9 \\
1.4 \\
6.1\end{array}$ \\
\hline
\end{tabular}

${ }^{1}$ Two patients had emboli after the onset of atrial fibrillation during the post-operative period.

${ }^{2}$ Includes one post-operative embolus.

A history of systemic embolism was given by 35 patients $(13.1 \%)$, of whom eight were in regular cardiac rhythm. The embolus was cerebral in 24 patients, peripheral in four, visceral in two, and multiple in five patients. Operative embolism occurred in two of those with a previous embolic history, all of whom had received anticoagulant therapy, many for long periods.

Clot in the atrium or atrial appendage was found at operation in 44 patients $(16.5 \%)$, of whom only six were in sinus rhythm. Thirty-four patients were under anticoagulant therapy. The relative frequency of fresh or old clot cannot be accurately given in this retrospective survey, but it is certainly unusual to find fresh clot in a patient having anticoagulants. Patients with a scarred or contracted appendage are included among those with old clot.

Ten of the 44 patients with atrial clot gave a history of systemic embolism and six suffered an embolus at operation. These 44 patients constitute one-sixth of the total cases yet provide nearly one-third of the pre-operative emboli and nearly one-half of the operative emboli, indicating that atrial clot is a significant factor in operative and non-operative embolism. 
RESULTS

The incidence of operative and post-operative systemic embolism in relation to cardiac rhythm and anticoagulant therapy is shown in Table V.

T A B L E V

INCIDENCE OF OPERATIVE SYSTEMIC EMBOLISM

\begin{tabular}{|c|c|c|c|c|c|c|}
\hline & \multicolumn{2}{|c|}{ Regular Rhythm } & \multicolumn{2}{|c|}{$\begin{array}{c}\text { Atrial } \\
\text { Fibrillation }\end{array}$} & \multirow{2}{*}{\multicolumn{2}{|c|}{ Total }} \\
\hline & \multirow{2}{*}{$\begin{array}{l}\text { Antico- } \\
\text { agulants }\end{array}$} & \multirow{2}{*}{$\begin{array}{c}\text { No } \\
\text { Antico- } \\
\text { agulants }\end{array}$} & \multirow{2}{*}{$\begin{array}{l}\text { Antico- } \\
\text { agulants }\end{array}$} & \multirow{2}{*}{$\mid \begin{array}{c}\text { No } \\
\text { Antico- } \\
\text { agulants }\end{array}$} & & \\
\hline & & & & & No. & $\%$ \\
\hline $\begin{array}{l}\text { No. of patients. } \\
\text { Operative emboli } \\
\text { Embolic deaths }\end{array}$ & $\begin{array}{r}35 \\
0 \\
0\end{array}$ & $\begin{array}{c}1 \mathrm{i1} \\
5^{1} \\
0\end{array}$ & $\begin{array}{c}114 \\
8^{2} \\
3\end{array}$ & $\begin{array}{l}7 \\
0 \\
0\end{array}$ & $\begin{array}{r}267 \\
13 \\
3\end{array}$ & $\begin{array}{r}4.9 \\
1.1\end{array}$ \\
\hline
\end{tabular}

${ }^{1}$ Two patients had emboli following post-operative atrial fibrillation.

${ }^{3}$ Includes one post-operative embolus.

There were 13 emboli, of which 12 were cerebral, causing three deaths, and one was brachial. Of the 10 survivors, five suffered a severe or substantial permanent disability and five made a complete or almost complete recovery.

Anticoagulant therapy was given to 114 patients in atrial fibrillation, but failed to prevent embolism in eight of them. These anticoagulant failures will be described in detail later. Seven patients with atrial fibrillation were not given anticoagulants for various reasons.

OTHER FACTORS IN EMBOLUS FORMATION Patients with severe disability are more likely to suffer an operative embolus; there were four emboli among 20 patients with grade 4 disability, an incidence of $20 \%$. Mitral incompetence also was associated with an increased risk of embolism; five emboli occurred in 52 patients found at operation to have a regurgitant jet.

Calcification of the mitral valve doubled the expected incidence of embolism; it was found in 94 patients $(35 \%)$, of whom 10 developed systemic emboli. Calcific emboli have been described by Bolton, Maniglia, and Massey (1952) and Uglov and Potashov (1962), and have been suspected by other authors when embolism occurs in the absence of atrial clot. The incidence of calcification, atrial clot, and systemic embolism in the present series is shown in Table VI, and is compared with the expected incidence in the whole series.

These figures show that whereas the incidence of atrial clot and pre-operative embolism was slightly raised in the presence of calcification, the incidence of operative embolism was more than
T A B L E V I

INCIDENCE OF CALCIFICATION

\begin{tabular}{|c|c|c|c|}
\hline & \multicolumn{2}{|c|}{ Patients } & \multirow{2}{*}{$\begin{array}{l}\text { Expected } \\
\text { Incidence } \\
(\%)\end{array}$} \\
\hline & No. & $\%$ & \\
\hline $\begin{array}{l}\text { Calcification } \\
\text { With atrial fibrillation } \\
\text { With atrial clot } \\
\text { With pre-operative embolus } \\
\text { With operative embolus } \ldots\end{array}$ & $\begin{array}{l}94 \\
43 \\
18 \\
14 \\
10\end{array}$ & $\begin{array}{l}46 \\
19 \\
15 \\
11\end{array}$ & $\begin{array}{l}45 \\
16 \cdot 5 \\
13 \\
5\end{array}$ \\
\hline
\end{tabular}

doubled. This suggests that some of these emboli may have been caused by calcific fragments, but this has not been proved by embolectomy or necropsy. All three patients in this series who died of systemic embolism had calcified valves, but necropsy revealed clot emboli only.

ANTICOAGULANT FAILURES No operative embolism affected patients in sinus rhythm who were having anticoagulant therapy. Eight patients with atrial fibrillation suffered a cerebral embolus, seven at operation and one on the second post-operative day. Four of these had grade 4 disability, and in five the anticoagulant therapy was unsatisfactory by the standards in use at the time (Table VII).

T A B L E V I I

ANTICOAGLUANT FAILURES

\begin{tabular}{c|c|c|c|c|c}
\hline & $\begin{array}{c}\text { Opera- } \\
\text { tive } \\
\text { Emboli }\end{array}$ & $\begin{array}{c}\text { Grade 4 } \\
\text { Dis- } \\
\text { ability }\end{array}$ & $\begin{array}{c}\text { Previous } \\
\text { Embolus }\end{array}$ & $\begin{array}{c}\text { Atrial } \\
\text { Clot }\end{array}$ & Deaths \\
\hline $\begin{array}{c}\text { Satisfactory } \\
\text { anticoagulants }\end{array}$ & 3 & 2 & 1 & 3 & 2 \\
$\begin{array}{c}\text { Unsatisfactory } \\
\text { anticoagulants }\end{array}$ & 5 & 2 & 0 & 3 & 1 \\
\hline Totals & 8 & 4 & 1 & 6 & 3 \\
\hline
\end{tabular}

The incidence of operative embolism in grade 4 cases was $20 \%$, which is four times the incidence in the whole series, and these emboli constituted half the total occurring in those with atrial fibrillation. Excluding the grade 4 cases, the group with atrial fibrillation had no higher incidence than the accepted good risk patients in sinus rhythm, and three of the four cases of embolism in this group were associated with unsatisfactory anticoagulation.

Of the five patients whose therapy was unsatisfactory, four had fluctuating or insufficiently depressed prothrombin levels and one had had therapy for only one week before operation. This patient is of particular interest, since the level of prothrombin activity on the morning of operation was $17 \%$ and yet fresh clot was found in the atrium. Another patient died of a cerebral 
embolus and necropsy showed multiple old and fresh emboli, although no history of pre-operative embolism had been given. Glenn and Holswade (1960) state that small emboli are often multiple and may be followed later by larger emboli. It seems more probable, however, that small emboli cause progressive damage to the arterial bed until a further small embolus causes infarction. In support of this, it is not unusual for an embolus to repeat the disability of an earlier one.

THROMBOPHLEBITIS AND PULMONARY EMBOLISM Patients who gave a history of thrombophlebitis or pulmonary embolism, or who were liable to develop these complications owing to pulmonary hypertension, received anticoagulant therapy irrespective of the cardiac rhythm.

Post-operative thrombophlebitis occurred in 10 patients, of whom four were having anticoagulants. Pulmonary embolism occurred after operation in 11 patients, of whom five were receiving anticoagulants. There was one death in a patient who was in regular rhythm at operation and who was given anticoagulants only after operation for atrial fibrillation with congestive heart failure.

COMPLICATIONS OF ANTICOAGULANT THERAPY Haemorrhage was the only serious complication encountered, and of five deaths from this cause in the whole series two were thought possibly to be due to the reduced clotting power of the blood. These two cases are now described.

Case 1 A woman of 43 years received anticoagulant therapy for two weeks before operation, on the morning of which her prothrombin level was $26 \%$. Operation disclosed a tight mitral stenosis with calcification but no incompetence. Transventricular valvotomy was followed by a considerable haemorrhage, after control of which an episode of ventricular fibrillation was terminated electrically. After repair of the atrial and ventricular incisions a persistent oozing haemorrhage occurred from all stitch holes and was not completely controlled at the time of wound closure. After operation intercostal drainage was heavy, and despite transfusion and vitamin $\mathbf{K}$ she died four hours later. The plasma fibrinogen measured post-operatively was within normal limits, but platelet counts were not done.

Case 2 A man of 37 years suffered a hemiplegia, after which he received anticoagulant therapy for one month until the day of operation, when the prothrombin level was $22 \%$. A transventricular valvotomy was performed for tight mitral stenosis without incompetence or calcification. He failed to recover conscious- ness and died four hours later. Necropsy revealed an extradural haemorrhage caused by a bleeding emissary vein.

There was usually no increased haemorrhage in patients having anticoagulants nor a noticeable increase in post-operative drainage. But, of 29 patients whose prothrombin level was below $30 \%$ on the day of operation, three suffered a haemothorax, of which two were evacuated surgically. Prothrombin levels have been measured during operation and usually show a rise of between $10 \%$ and $20 \%$ before the closure of the incision, with a further small rise by the next day. This effect may be due to the transfused blood and reduces the danger of haemorrhage during and after the operation.

\section{DISCUSSION}

Ricordeau and Balansa (1957), Storm (1958), Goodwin (1960), and Uglov and Potashov (1962) have given anticoagulants in preparation for mitral valvotomy and have had considerable success in reducing the incidence of embolism. Phenindione was mostly used but was usually discontinued before operation. Uglov and Potashov (1962) treated 76 patients suspected of having atrial clot and compared them with 78 similar but untreated patients. Of those treated, three had fresh atrial clot and one suffered an embolus at operation, but of those untreated, 27 had fresh atrial clot and eight developed emboli. There were two deaths from haemorrhage in the post-operative period, during which heparin was substituted for phenindione.

In the present series, anticoagulant therapy has been used in a wider selection of cases, including nearly all patients with irregular rhythm who have undergone mitral valvotomy since 1955. The assessment of results is difficult in the absence of controls, but the figures for the series as a whole give some indication of the effectiveness or otherwise of this therapy. Since the start of the anticoagulant regime, and without regard to the cardiac rhythm, the incidence of operative embolism has been $4.9 \%$, with a mortality of $1.1 \%$. This death rate is lower than in any published series in which anticoagulants have not been used. Anticoagulants failed to prevent embolism in eight patients, of whom three were having apparently satisfactory therapy, but two of these had a grade 4 disability.

The protection given by anticoagulants must be set against the complications, which included two deaths from haemorrhage in patients with pro- 
thrombin levels below $30 \%$ on the day of operation. These deaths might have been avoided by adhering more closely to the planned regime, but one followed a severe operative haemorrhage and the anticoagulation was not necessarily a major factor. Our present practice is to give anticoagulants for at least two weeks and to allow the prothrombin level to rise to over $40 \%$ on the morning of operation, lowering it again for the post-operative period.

The future policy at this hospital will be to continue to give anticoagulant therapy in preparation for mitral valvotomy to all patients with atrial fibrillation, pulmonary hypertension, or a history of embolism or thrombophlebitis. Our experience has shown, however, that steady control of the prothrombin level is sometimes difficult, especially in so short a period as two weeks and in patients with heart failure or liver damage. The supervision of therapy in these patients has been close, but good control has not always been obtained. Other difficulties that arise are due to the prolonged stay in hospital, and impatience on the part of the patient or surgeon must be resisted if an adequate anticoagulant regime is to be carried out.

\section{CONCLUSIONS}

Operative embolism is a major risk in grade 4 cases, and satisfactory anticoagulation does not afford adequate protection.

Provided anticoagulant therapy is satisfactory, the risk of operative embolism can be reduced to a fraction of the accepted level.

Failures in spite of satisfactory anticoagulation may be due to calcific embolism, but this cannot definitely be established.

The high incidence of atrial clot in patients with a past history of embolism and with operative embolism indicates that the atrium is the major source and that anticoagulant therapy is a rational procedure.

\section{SUMMARY}

The incidence of systemic embolism complicating mitral valvotomy is reviewed; in this series of
267 patients who underwent the operation between 1955 and 1963 it occurred in $13(4.9 \%)$, with a mortality of three $(1 \cdot 1 \%)$.

Anticoagulants have been widely used before and after operation in patients with atrial fibrillation, and in patients in sinus rhythm with pulmonary hypertension, thrombo-phlebitis, or a history of systemic or pulmonary embolism.

Adequate anticoagulant therapy is shown to give good protection against operative embolism except in patients with grade 4 disability, and the control and dangers of this therapy are discussed.

I am grateful to Dr. P. H. Davison for constructive advice, and to Professor A. L. D'Abreu, Mr. S. J. MacHale, Mr. K. D. Roberts, and Dr. D. J. S. McIlveen for allowing me to review their cases.

\section{REFERENCES}

American College of Chest Physicians, Report of the Section on Cardiovascular Surgery (1959). The surgical treatment of mitral stenosis. Dis. Chest, 35, 435.

Baker, C., Brock, R. C., Campbell, M., and Wood, P. (1952). Valvotomy for mitral stenosis. Brit. med. J., 1, 1043.

Belcher, J. R., and Somerville, W. (1955). Systemic embolism and left auricular thrombosis in relation to mitral valvotomy. Ibid., 2, 1000

Bolton, H. E., Maniglia, R., and Massey, F. C. (1952). Calcific emboli complicating mitral valve commissurotomy. J. thorac. Surg., 24, 502 .

Foley, W. T., and Wright, I. S. (1956). The use of anticoagulants. An evaluation. Med. Clin. N. Amer., 40, 1339

Glenn, F., and Holswade, G. R. (1960). Emboli in the surgical treatment of mitral stenosis. Surg. Gynec. Obstet., 111, 289.

Glover, R. P., Iaia, B., O'Neill, J. E., and Janton, O. H. (1955). In Thrombose und Embolie (Proc. Ist int. Congr., Basel, 1954), p. 1173. Schwabe, Basel.

Goodwin, J. F. (1960). Treatment of peripheral vascular disease. $1-$ Medical. In Pathogenesis and Treatment of Occlusive Arterial Disease (Proc Conference London, 1959, ed. L. McDonald), p. 217. Pitman Medical Publ. Co., London.

Kellogg, F., Liu, C. K., Fishman, I. W., and Larson, R. (1961). Systemic and pulmonary emboli before and after mitral com missurotomy. Circulation, 24, 263.

Logan, A., and Turner, R.(1959). Surgical treatment of mitral stenosis. Lancet, 2, 874

Ricordeau, G., and Balansa, J. (1957). Thrombose auriculaire et 음 traitement préopératoire de la sténose mitrale. Presse méd., 65, 1730 .

Scannell, J. G., Burke, J. F., Saidi, F., and Turner, J. D. (1960). Five-year follow-up of closed mitral valvulotomy. J. thorac.

Surg., 40,723.
Storm, O. (1958). Anticoagulant protection in surgery. Thrombos. O Diathes. haemorrh. (Stuttg.), $2,484$.

Szekely, P. (1964). Systemic embolism and anticoagulant prophylaxis $N$ in rheumatic heart disease. Brit. med. J., 1, 1209

Uglov, F. G., and Potashov, L. V.(1962). The prophylaxis of thrombo- N embolic complications in surgery for mitral stenosis. $J$. thorac. Surg., 44, 408

Wood, P. (1954). An appreciation of mitral stenosis. Brit. med. J., 1, 1051 . 